\title{
Tactical rule and pitch size change the physical and technical performance of young soccer players during small-sidded games
}

\section{A regra tática e o formato do campo mudam o desempenho físico e técnico de jovens jogadores de futebol durante jogos reduzidos}

\author{
José Francisco de Sousa Neto Segundo ${ }^{1}$ \\ (D) https://orcid.org/0000-0002-3712-6673 \\ Jefferson Pitz Vieira ${ }^{1}$ \\ (D) https://orcid.org/0000-0002-0852-6846 \\ Arthur Pereira Ventura \\ (D) https://orcid.org/0000-0002-3237-8871 \\ João Vitor Wan-zuit \\ (D) https://orcid.org/0000-0002-8244-7660 \\ Guilherme Souza Pereira \\ (D) https://orcid.org/0000-0003-0415-2389 \\ Pedro Henrique Cangiani Sanches \\ (D) https://orcid.org/0000-0001-6172-7017 \\ Anderson Santiago Teixeirat, \\ (I) https://orcid.org/0000-0001-7508-9917 \\ Juliano Fernandes da Silva \\ (D) https://orcid.org/0000-0002-6017-7145
}

Abstract - The present study examined the effects of small-sided and conditioned games (SSCGs) manipulating tactical rules (ball-possession [BP] vs goal-scoring with goalkeepers [GS]) and pitch size (square [SP] vs rectangular [RP]) on the running performance and technical skills of young soccer players. Ten male soccer players (chronological age: $12.45 \pm$ 0.51 years; body mass: $41.99 \pm 7.97 \mathrm{~kg}$; height: $152.85 \pm 10.03 \mathrm{~cm}$ ) were monitored using GPS units during SSCG formats. The distance covered at different running intensities and number of technical actions were used in analyses. SSCG-induced changes in $30 \mathrm{~m}$ sprint and CMJ performances were also evaluated. Compared to BP, GS elicited significantly lower distances covered at low intensity running ( $\mathrm{p}=0.003 ; d=-0.95)$, more sprints $(\mathrm{p}=0.050 ; d=0.67)$, and longer distances covered in terms of walking $(\mathrm{p}=0.035 ; d=2.60)$ and sprinting $(\mathrm{p}=0.029 ; d=0.75) ;$ (ii) number of passes (short $[\mathrm{p}=0.002 ; d=1.10]$ and long $[\mathrm{p}=0.013 ; d=0.82]$ ) were more frequent during BP than GS games, while RP game format allowed for greater occurrence of long passes ( $\mathrm{p}=0.036 ; d=0.64$ ) than under the SP condition; (iii) jumping and sprinting performance did not change ( $p>0.05$ ) using different SSCG formats. In conclusion, GS games demand more sprint running episodes in terms of number and distance covered than BP games. In addition, RP game formats can be used to increase the occurrence of longer passes in young soccer players aged $11-13$ years.

Key words: Games, experimental; Monitoring; Soccer; Task performance and analysis.

Resumo - O estudo examinou os efeitos de diferentes jogos reduzidos e condicionados (JRC): manipulando as regras táticas (posse de bola (BP) vs. marcar gols com goleiro (GS)) e o formato do campo (quadrado vs. retangular) sobre o desempenho físico e técnico em jovens jogadores de futebol. Dez jogadores do sexo masculino (idade: 12,45 $\pm 0,51$ anos; massa corporal: 41,99 \pm 7,97 kg; altura: 152,85 \pm $10,3 \mathrm{~cm}$ ) foram monitorados a través do sistema de posicionamento global e os JRC gravados em vídeo. A distância percorrida em diferentes intensidades e o número de açôes técnicas para os 4 diferentes JRC foram usadas para análise. O efeito dos JRC sobre o desempenho no teste de sprints de 30 m e altura do salto vertical também foram analisadas. Os JRC para GS provocaram distâncias significativamente menores em corrida de baixa intensidade ( $p=0.003 ; d=-0.95)$ e mais sprints $(p=0.050 ; d=0.67)$ e maiores distâncias caminhando $(p=0.035 ; d=2.60)$ e em sprint $(p=0.029 ; d=0.75)$ comparado ao BP; (ii) o número de passes (curtos [ $p=0.002 ; d=1.10]$ e longos $[p=0.013 ; d=0.82]$ ) é maior nos $J R C$ de $B P$ que GS. O formato retangular permite maior ocorrência de passes longos que o modelo quadrado ( $p=0.036 ; d=0.64$ ); (iii) o desempenho de salto vertical e velocidade não mudou $(p>0.05)$ após os JRC. Concluindo, açôes envolvendo sprints em número e distância são maiores no JRC com GS comparado ao BP, enquanto que JRC de BP favorecem o desenvolvimento do passe. Por fim, o campo retangular com BP estimula a realização de passes mais longos em jovens jogadores.

Palavras-chave: Análise e desempenho de tarefas; Futebol; Jogos experimentais; Monitoramento.
1 Universidade Federal de Santa Catarina. Núcleo de Pesquisa e Desenvolvimento do Futebol e Futsal. Florianópolis, SC. Brasil.

2 Universidade Federal de Santa Catarina. Laboratório de Esforço Físico. Florianópolis, SC.Brasil.

Received: December 05, 2019 Accepted: August 28, 2020

How to cite this article Segundo JFSN, Vieira JP, Ventura AP, Wan-zuit JV, Pereira GS, Sanches PHC Teixeira AS, Silva JF. Tactical rule and pitch size change the physical and technical performance of young soccer players during small-sided games. Rev Bras Cineantropom Desempenho Hum 2021, 23:e70479. D0l: http://doi. org/10.1590/1980-0037.2021v23e70479

Copyright: This work is licensed under a Creative Commons Attribution 4.0 International License. 


\section{INTRODUCTION}

The deep knowledge of match demands imposed on young soccer players is essential to optimize training interventions and to assess the potential of each player in their respective stage of development ${ }^{1}$. Youth soccer is characterized by lower absolute and relative physical and technical demand compared to elite level ${ }^{2}$. Available data suggest that the total distance covered during a match increases with age, with sprinting activities and high-intensity running (HIR) episodes accounting for approximately 3-9\% and $9-16 \%$ of the total match distance, respectively ${ }^{2-4}$. With regard to technical involvement, previous study showed that some technical actions such as passes, successful passes completed (\%), and ball touches are increased with age ${ }^{2}$. These data are of practical relevance to aid coaches and sports scientists with the development of soccer-specific training sessions in order to prepare athletes to deal with physical and technical-tactical demands experienced in an official match scenario.

Small-Sided and Conditioned Games (SSCGs) are typically described as smaller versions of the formal game ${ }^{5}$. SSCGs are a training method commonly used by coaches to optimize the training time, physiological/physical attributes, and technical-tactical components using an integrative training approach, thus respecting one of the main principles of sports training: specificity $^{5}$. Previous studies have indicated that the SSCG intensity is affected by manipulating a variety of variables such as pitch dimensions (size and format), number of players, use of floaters, ball-possession (BP), goal-scoring (GS) using goalkeepers (GKs), number of ball touches, coach encouragement, and so on ${ }^{6-8}$.

According to current long-term athlete development programs, the use of SSCGs should preferentially be prioritized rather than running-based training in young players including years of sport initiation and specialization (11-13 years) ${ }^{9}$. SSCGs are considered advantageous training modalities, allowing players to train their physical, technical, and tactical capabilities concomitantly, while remaining motivated and frequently experiencing different game situations ${ }^{10}$. However, some SSCG limitations have been highlighted, especially with regard to not being able to replicate an official full match in terms of distances covered in HIR and sprinting activities in soccer players ${ }^{11}$.

Among the several possibilities of variables that can be manipulated to design SSCGs, pitch dimension, classified as a structural element ${ }^{12-14}$, and goal-scoring (GS) or ball-possession (BP), recognized as tactical goals of the game, have received some attention in literature ${ }^{13,15,16}$. The former involves modifications in pitch length and width and the relative space per player. The latter modifies the tactical goal of the game. Available current evidence indicates that SSCGs played in larger areas and aimed at GS result in greater workloads in terms of HIR and sprinting activities ${ }^{11-13,17}$. On the other hand, smaller SSCGs induce greater player load (i.e., acceleration sum) and more acceleration-deceleration events $\left(2-3 \mathrm{~m} \cdot \mathrm{s}^{-2}\right)$ than 
larger pitches ${ }^{11,13}$. Meantime, BP games elicited greater metabolic and cardiovascular demand than GS games ${ }^{15,18}$.

Based on these findings, the assumption that manipulating these structural and tactical elements during SSCGs will influence the physical and technical requirements during SSCGs in younger soccer players is plausible. Indeed, this has been previously investigated in senior players by Gaudino et al. ${ }^{13}$. However, relative pitch area per player was not kept constant ( 75 vs 98 vs $135 \mathrm{~m}^{2}$ ) in that study. Thus, studies using similar playing surface per player are necessary to better understand how rectangular $[\mathrm{RP}]$ vs square $[\mathrm{SP}]$ pitches can influence the physical and technical demand in SSCGs organized for GS or maintaining BP. For instance, $\mathrm{RP}$ elicits more distance at higher intensities, passes and dribbles than SP format during SSCG developed for GS $(\mathrm{GK}+4 \mathrm{vs} 4+\mathrm{GK})^{17}$. Whether the same results are observed under RP condition during SSCG organized for maintaining BP are not yet known. Additionally, the majority of aforementioned studies were conducted with older adolescent (16-18 years) and senior players ${ }^{11-13,15,18}$, while information on players in the early ages of the training process (11-13 years) is scarcer. Younger players show distinct physical and technical-tactical responses to SSCGs compared to their older and more experienced teammates ${ }^{19,20}$. Furthermore, some investigations have revealed that SSCGs can induce a decrement in speed-power related abilities (e.g., $30 \mathrm{~m}$ sprint time and countermovement [CMJ] height) after different SSCG formats in soccer players ${ }^{21-23}$. However, the effects of SSCGs with varying pitch size and tactical rules on the neuromuscular abilities of young players in the early ages of adolescence (11-13 years) are less evident. Knowing whether SSCGs are fatiguing or non-fatiguing games can aid coaches to better decide which day these activities are more appropriate within the micro-cycle of novice players. In a practical setting, fatiguing activities are not advised in sessions before (match day minus 1 and 2) or after a match ${ }^{23}$.

Thus, the aim of this study was to examine the effects of manipulating tactical rules (GS or $\mathrm{BP}$ ) and pitch size (SP or RP) and their combined effects on the running performance and technical skills of young soccer players aged 11.29-13.00 years. This study also investigated SSCG-induced changes in neuromuscular performance assessed using 30-m sprint time and CMJ height.

\section{METHODS}

\section{Participants}

Ten male young soccer players (chronological age: $12.45 \pm 0.51$ years; body mass: $41.99 \pm 7.97 \mathrm{~kg}$; height: $152.85 \pm 10.03 \mathrm{~cm}$ ) were recruited from a professional club competing at the Brazilian national level. Players were classified as Under 13 by the Soccer Federation of Santa Catarina (member of the Brazilian Soccer Confederation). At the time of the study, all players had at least 1 year of experience in soccer training and participated in 
regional and national championships. Players performed 3 regular training weekly sessions (about 60-90 minutes) and participated in official games, usually on Saturdays or Mondays. Club, players, and their parents or legal guardians provided written informed consent. Participants were informed about the nature of the study; participation was voluntary and players could withdraw at any time. This study was approved by the Ethics Committee of the Local University (No. 2.572.259).

\section{- 30-m sprint and Countermovement Jump (CMJ) tests}

30-m sprint and CMJ tests were performed before (pre) the first SSCG condition and immediately after each SSCG condition to identify possible game-induced changes in sprint and jump performance, respectively. To determine the maximal sprinting speed of each player, four pairs of photocells (Microgate Witty-Gate) were positioned at distances of $0 \mathrm{~m}, 10 \mathrm{~m}$, $20 \mathrm{~m}$, and $30 \mathrm{~m}$ along the sprinting course ( $1 \mathrm{~m}$ from the floor) before the execution of tests. Players performed two attempts, starting from standing position $0.3 \mathrm{~m}$ behind the start line. A 3-minute rest interval was allowed between the two attempts, and the fastest 10-m time was used in analyses.

In CMJ, players were instructed to execute a downward movement followed by complete extension of legs and were free to determine the countermovement amplitude to avoid changes in jumping coordination. CMJ was executed with hands fixed on hips. All jumps were performed on a jumping mat (Elite Jump ${ }^{\circledR}$ ). Each player executed five vertical jumps. Successive attempts were interspersed with 15 second rest. Data were obtained using the Elite Jump V2.10 software, and the best CMJ attempt was selected for analysis.

\section{- Time-Motion Characteristics}

To quantify the physical demands of soccer players in each SSCG format, global positioning system (GPS) with $10-\mathrm{Hz}$ resolution (K-Sport, Montellabate, Italy) was used ${ }^{12}$. GPS was fixed at the top of each player's back using adjustable neoprene vest. After SSCG protocols, data were downloaded to a computer and analyzed using a customized software package (Prozone ${ }^{\circledR}$, Leeds, England). The objective measures of physical performance during SSCG formats were derived from seven running speed zones as previously proposed by Castagna et al. ${ }^{3}$ : standing [S] (0 to $\left.0.4 \mathrm{~km} \cdot \mathrm{h}^{-1}\right)$, walking [W] $\left(0.4\right.$ to $3 \mathrm{~km}^{-1} \mathrm{~h}^{-1}$, low-intensity running [LIR] ( 3 to $\left.8 \mathrm{~km} \cdot \mathrm{h}^{-1}\right)$, mediumintensity running [MIR] (8 to $\left.13 \mathrm{~km} \cdot \mathrm{h}^{-1}\right)$, high-intensity running [HIR] (13 to $\left.18 \mathrm{~km} \cdot \mathrm{h}^{-1}\right)$, sprint $\left(>18 \mathrm{~km} \cdot \mathrm{h}^{-1}\right)$, and high-intensity activities [HIA] $\left(>13 \mathrm{~km} \cdot \mathrm{h}^{-1}\right)$.

\section{- Small sided and conditioned games (SSCG)}

In this study, two different tactical rules (goal-scoring [GS] vs ball-possession $[\mathrm{BP}]$ ) and two distinct pitch size (square pitch - SP [length $\mathrm{x}$ width: $38.5 \times 38.5 \mathrm{~m}]$ vs rectangular pitch - RP [48.0 x $31.0 \mathrm{~m}])$ were manipulated to compare time-motion responses and technical actions during four types 
of 5 vs 5 SSCGs. Games were played (i) on square pitch for goal-scoring $(\mathrm{SP}+\mathrm{GS}: 5$ vs $5+\mathrm{GK})$ or to maintain ball possession (SP + BP: 5 vs 5 without GK); (ii) on rectangular pitch for goal-scoring (RP + GS: 5 vs 5 $+\mathrm{GK})$ or to maintain ball possession (RP + BP: 5 vs 5 without GK). The duration of each game format was set at 20 minutes. Games consisted of two halves of 10 minutes, with 5-minute half-time passive rest period (2:1 work-to-rest ratio). Relative pitch area of approximately $148 \mathrm{~m}^{2}$ per player (only outfield players) was maintained, as well as length/width ratios of approximately o 1.0 and $1.54 \mathrm{~m}$ for SP and RP, respectively. The head coach organized teams according to playing positions, technical-tactical level, playing experience, and aerobic fitness. The head coach also provided verbal encouragement and introduced balls immediately when the ball left the playing field.

\section{Analysis of technical components}

Soccer-specific technical skills were evaluated through the analysis of game footage, as described in previous studies with soccer players ${ }^{24}$. A digital video camera (Canon EOS Rebel $\mathrm{T} 6 \mathrm{i}^{\circledR}$ ) was positioned to frame all four corners of the field in order to record the technical actions performed by players during SSCG formats. According to previous studies, the main technical skills commonly performed during game situations were as follows: short passes, long passes, dribbling, shots on target, tackles, and interception. Intraclass Correlation Coefficient (ICC) was calculated to evaluate intra-rater consistency measures for the analysis of technical components ( $25 \%$ of overall technical actions). ICC values for intra-observer reliability for technical actions were as follows: short passes (0.98), long passes (0.96), dribbling (0.96), shots on target (1.0), tackles (0.96), and interception (0.95).

\section{Statistical analysis}

Data are presented as mean \pm standard deviation. The Shapiro-Wilk test was used to test data normality. The Levene's test was used to test whether variance homogeneity was assumed. Mixed model analysis was performed for GPS-based running performance and technical variables, assuming pitch size (RP or SP) and tactical rule (BP or GS) as fixed factors, and participants as random factor. One-way repeated measures analysis of variance (ANOVA) was also used to identify any difference between SSCG formats for sprint time and CMJ height measures. Whenever significant F-value was obtained, post hoc test with Bonferroni adjustment was performed for multiple comparison. In addition, paired Student t-test was used to compare the technical action of shots on target during RP and SP modes. The magnitude of differences was assessed using standardized mean differences (Cohen's d effect size, ES) with thresholds of 0.20, 0.60, 1.20, 2.0 , and 4.0 for small, moderate, large, very large, and extremely large ${ }^{25}$. Statistical analyses were carried out using SPSS statistical analysis software (SPSS version 17.0, Chicago, USA). Significance level was set at $\mathrm{p} \leq 0.05$. 


\section{RESULTS}

In the present study, there were no significant pitch size /tactical rule interaction effects for GPS-based physical and technical performance measures (Table 1).

Distances covered in each running speed zone during all SSCGs formats are presented in Table 1. Significant main effect of tactical rule was found for walking $\left(\mathrm{F}_{(1,30.784)}=4.864 ; \mathrm{p}=0.035\right)$, sprinting distance $\left(\mathrm{F}_{(1,22.017)}=5.456 ; \mathrm{p}=0.029\right)$, and number of sprints $\left(\mathrm{F}_{(1,25.434)}=4.136 ; \mathrm{p}\right.$ $=0.050)$. Post-hoc analysis indicated that players traveled significantly longer distances walking $(\mathrm{p}=0.035 ; d=2.60)$ and sprinting $(\mathrm{p}=0.029 ; d$ $=0.75$ ) during GS compared to BP regardless of pitch size. Furthermore, GS elicited significantly $(\mathrm{p}=0.050 ; d=0.67)$ greater number of sprints compared to the $\mathrm{BP}$ condition. There was also significant main effect of pitch size $\left(\mathrm{F}_{(1,32.321)}=6.362 ; \mathrm{p}=0.017\right)$ and tactical rule $\left(\mathrm{F}_{(1,32.321)}=9.952\right.$; $\mathrm{p}=0.003)$ for LIR. Post-hoc analyses revealed that distances covered in LIR were significantly lower during RP compared to SP ( $\mathrm{p}=0.017 ; d=$ -0.72), as well as during GS compared to the BP condition ( $\mathrm{p}=0.003$; $d$ $=-0.95)$. No significant main effects $(p>0.05)$ of pitch size or tactical rule were found for the other GPS-derived physical performance measures .

Technical performance measures during each SSCG format are shown in Table 2. Significant main effect of tactical rule (GS and BP) was found for short pass $\left(\mathrm{F}_{(1,31.904)}=11.523 ; \mathrm{p}=0.002\right)$ and long pass $\left(\mathrm{F}_{(1,16.658)}=7.772\right.$; $\mathrm{p}=0.013)$. Post-hoc analysis showed that players performed significantly

Table 1. Statistical descriptive (mean + SD) for GPS-derived physical performance parameters during the four SSCG formats, and F and $p$-value for main effects and interaction effects obtained from Mixed Model Analysis $(n=10)$.

\begin{tabular}{|c|c|c|c|c|c|c|c|c|c|c|}
\hline \multirow[b]{3}{*}{$\begin{array}{l}\text { Catego- } \\
\text { ries }\end{array}$} & \multicolumn{4}{|c|}{ Small-Sided and Conditioned Games (SSCG) } & \multicolumn{6}{|c|}{ Mixed Models } \\
\hline & \multicolumn{2}{|c|}{ Square Field (SF) } & \multicolumn{2}{|c|}{ Rectangular Field (RF) } & \multicolumn{2}{|c|}{$\begin{array}{l}\text { Field Dimen- } \\
\text { sion Effect }\end{array}$} & \multicolumn{2}{|c|}{$\begin{array}{c}\text { Tactical Rule } \\
\text { Effect }\end{array}$} & \multicolumn{2}{|c|}{$\begin{array}{c}\text { Interaction } \\
\text { Effect }\end{array}$} \\
\hline & GS & $\mathrm{BP}$ & GS & BP & $\mathrm{F}$ & $\begin{array}{c}p- \\
\text { value }\end{array}$ & $\mathrm{F}$ & $\begin{array}{c}p- \\
\text { value }\end{array}$ & $\mathrm{F}$ & $\begin{array}{c}p- \\
\text { value }\end{array}$ \\
\hline $\mathrm{TD}(\mathrm{m})$ & $1777.66 \pm 152.20$ & $1833.43 \pm 169.47$ & $1663.44 \pm 180.03$ & $1825.44 \pm 189.48$ & 1.137 & 0.295 & 3.610 & 0.067 & 0.859 & 0.361 \\
\hline$S(m)$ & $7.48 \pm 1.35$ & $6.15 \pm 1.29$ & $7,25 \pm 2.03$ & $6.68 \pm 1.39$ & 0.087 & 0.769 & 3.569 & 0.069 & 0.566 & 0.458 \\
\hline W (m) & $132.20 \pm 33.66$ * & $106.30 \pm 32.94$ & $143.63 \pm 28.81$ * & $123.51 \pm 20.50$ & 1.884 & 0.180 & 4.864 & 0.035 & 0.077 & 0.784 \\
\hline $\operatorname{LIR}(\mathrm{m})$ & $671.33 \pm 76.40 * \dagger$ & $726.51 \pm 52.39 \dagger$ & $594.12 \pm 80.57^{\star}$ & $686.08 \pm 73.47$ & 6.362 & 0.017 & 9.952 & 0.003 & 0.622 & 0.463 \\
\hline $\begin{array}{l}\text { MIR } \\
(\mathrm{m})\end{array}$ & $693.02 \pm 141.07$ & $806.75 \pm 205.62$ & $651.21 \pm 157.00$ & $779.06 \pm 205.84$ & 0.334 & 0.568 & 4.039 & 0.055 & 0.014 & 0.907 \\
\hline $\mathrm{HIR}(\mathrm{m})$ & $236.72 \pm 88.99$ & $174.73 \pm 62.80$ & $230.48 \pm 116.20$ & $214.64 \pm 84.00$ & 0.332 & 0.569 & 1.772 & 0.193 & 0.623 & 0.436 \\
\hline $\begin{array}{l}\text { Sprint } \\
(\mathrm{m})\end{array}$ & $36.93 \pm 37.78$ * & $12.95 \pm 7.14$ & $36.72 \pm 37.59$ * & $19.07 \pm 15.63$ & 0.110 & 0.743 & 5.456 & 0.029 & 0.126 & 0.725 \\
\hline HIA (m) & $273.63 \pm 113.65$ & $187.67 \pm 65.49$ & $267.19 \pm 151.10$ & $230.13 \pm 96.91$ & 0.252 & 0.620 & 2.935 & 0.098 & 0.464 & 0.501 \\
\hline NS (n) & $3.30 \pm 2.45$ * & $1.75 \pm 0.46$ & $3.20 \pm 2.49$ * & $2.22 \pm 1.64$ & 0.090 & 0.767 & 4.136 & 0.050 & 0.212 & 0.649 \\
\hline $\begin{array}{l}\text { MS } \\
(\mathrm{km} . \\
\left.\mathrm{h}^{-1} 1\right)\end{array}$ & $20.85 \pm 1.89$ & $20.23 \pm 1.11$ & $21.79 \pm 1.93$ & $20.04 \pm 2.30$ & 0.392 & 0.536 & 3.824 & 0.060 & 0.854 & 0.363 \\
\hline
\end{tabular}

Note. GS: goal-scoring game; BP: ball-possession game; DT: total distance; S: standing; W: walking; LIR: low-intensity running; MIR: medium-intensity running; HIR: high-intensity running; HIA: high-intensity activities; NS: number of sprints, MS: maximal speed;

* significantly different from BP within the same field dimension $(p<0.05)$; $†$ significantly different from RF within the same tactical rule. 
more short ( $\mathrm{p}=0.002 ; d=1.10)$ and long passes $(\mathrm{p}=0.013 ; d=0.82)$ in BP than in GS regardless of pitch size. Significant main effect of pitch size (SP and RP) was also identified for long pass $\left(\mathrm{F}_{(1,16.658)}=5.179 ; \mathrm{p}=0.036\right)$. It was observed that SP elicited fewer long passes $(\mathrm{p}=0.036 ; d=-0.64)$ than $\mathrm{RP}$ within the same tactical rule.

Physical performance evaluated by means of $30-\mathrm{m}$ sprint time (panel a) and CMJ height (panel b) before and after each SSCG format is shown in Figure 1. One-way repeated measures ANOVA results showed that pre values for $30-\mathrm{m}$ sprint time $(5.14 \pm 0.24 \mathrm{~s})$ and $\mathrm{CMJ}$ height $(30.70 \pm 4.08$ $\mathrm{cm})$ did not differ ( $\mathrm{p}>0.05)$ from those observed after SP+GS (30-m sprint: $4.95 \pm 0.23 \mathrm{~s} ; \mathrm{CMJ}: 30.33 \pm 3.66), \mathrm{SP}+\mathrm{BP}(30-\mathrm{m}$ sprint: $4.96 \pm 0.24 \mathrm{~s}$; CMJ: $30.25 \pm 2.77 \mathrm{~cm}), \mathrm{RP}+\mathrm{GS}(30$-m sprint: $4.94 \pm 0.16 \mathrm{~s} ; \mathrm{CMJ}: 29.79 \pm 2.73)$, and $\mathrm{RP}+\mathrm{BP}(30$-m sprint: $4.95 \pm 0.26$; CMJ: $29.39 \pm 3.66)$ game formats.

\section{DISCUSSION}

This study examined the influence of manipulating tactical rules (GS or $\mathrm{BP}$ ) and pitch size (SP or $\mathrm{RP}$ ) and their combined effects on running performance and technical skills in young soccer players aged 11.29-13.00 years. SSCG-induced changes in 30-m sprint and CMJ performances were also evaluated. Results indicate that despite the similar playing surface,

Table 2. Statistical descriptive (mean + SD) for the technical performance parameters during the four SSCG formats, and F and $p$-value for main effects and interaction effects obtained from Mixed Model Analysis $(n=10)$.

\begin{tabular}{|c|c|c|c|c|c|c|c|c|c|c|}
\hline \multirow[b]{3}{*}{$\begin{array}{l}\text { Technical } \\
\text { Variables }\end{array}$} & \multicolumn{4}{|c|}{ Small-Sided and Conditioned Games (SSCG) } & \multicolumn{6}{|c|}{ Mixed Models } \\
\hline & \multicolumn{2}{|c|}{ Square Field (SF) } & \multicolumn{2}{|c|}{ Rectangular Field (RF) } & \multicolumn{2}{|c|}{$\begin{array}{l}\text { Field Dimen- } \\
\text { sion Effect }\end{array}$} & \multicolumn{2}{|c|}{$\begin{array}{c}\text { Tactical Rule } \\
\text { Effect }\end{array}$} & \multicolumn{2}{|c|}{$\begin{array}{l}\text { Interaction } \\
\text { Effect }\end{array}$} \\
\hline & GS & BP & GS & BP & $\mathrm{F}$ & $\begin{array}{l}p- \\
\text { value }\end{array}$ & $\mathrm{F}$ & $\begin{array}{l}p- \\
\text { value }\end{array}$ & $\mathrm{F}$ & $\begin{array}{l}p- \\
\text { value }\end{array}$ \\
\hline Short Pass & $12.67 \pm 6.46$ * & $22.40 \pm 7.52$ & $14.10 \pm 5.38$ * & $19.80 \pm 8.65$ & 0.066 & 0.799 & 11.523 & 0.002 & 0.787 & 0.382 \\
\hline Long Pass & $1.44 \pm 1.42{ }^{*} \dagger$ & $2.30 \pm 1.89 \dagger$ & $1.90 \pm 1.10$ * & $5.40 \pm 4.17$ & 5.179 & 0.036 & 7.772 & 0.013 & 2.865 & 0.109 \\
\hline Dribbling & $3.67 \pm 2.65$ & $3.70 \pm 2.79$ & $4.50 \pm 2.51$ & $3.70 \pm 2.79$ & 0.599 & 0.445 & 0.536 & 0.470 & 0.074 & 0.787 \\
\hline Tackle & $2.33 \pm 2.00$ & $2.00 \pm 1.83$ & $2.70 \pm 1.06$ & $2.30 \pm 1.57$ & 0.391 & 0.537 & 0.474 & 0.497 & 0.004 & 0.951 \\
\hline Interception & $1.56 \pm 1.33$ & $3.10 \pm 2.02$ & $1.80 \pm 1.23$ & $1.80 \pm 1.23$ & 1.225 & 0.278 & 2.662 & 0.116 & 2.662 & 0.116 \\
\hline Shots on Target & $2.10 \pm 1.59$ & n.a & $2.80 \pm 1.31$ & n.a & $1.106^{A}$ & $\underset{A}{0.305}$ & n.a & n.a & n.a & n.a \\
\hline
\end{tabular}

Note. n.a: not assigned; GS: goal-scoring game; BP: ball-possession game;

${ }^{*}$ significantly different from BP within the same field dimension $(\mathrm{p}<0.05)$; $†$ significantly different from $\mathrm{RF}$ within the same tactical rule; A: values were derived from paired Student t-test.
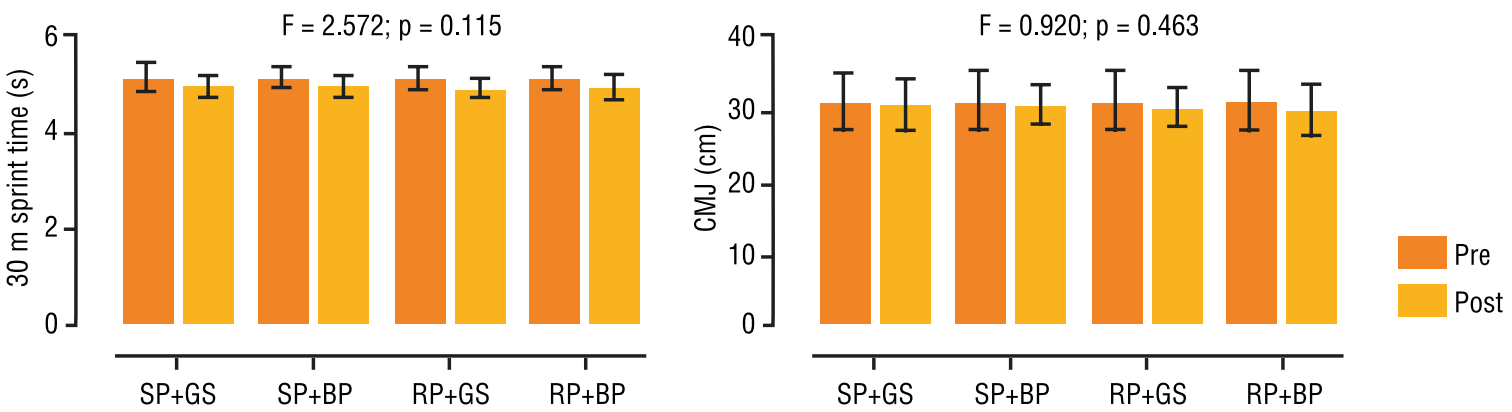

Figure 1. 30-m sprint time (panel A) and CMJ height (panel B) before and after each SSCGs format. Values are presented as mean \pm standard deviation. 
participants performed differently when modifying tactical rules or pitch size, suggesting different adaptive behaviors. Our main findings showed that: (i) SSCGs organized to score goals elicited significantly lower distances covered in LIR and more sprints and longer distance covered in terms of walking and sprinting; (ii) number of passes (short and long) are more frequent in SSCGs created to maintain ball-possession, while RP game format allows greater occurrence of long passes compared to the SP condition; (iii) jumping and sprinting performance did not change with different game formats, suggesting that power-speed related abilities were preserved in this sample.

It is well accepted that although DT covered is not directly related to decisive match situations, it is a useful parameter to monitor training volume ${ }^{3}$. The relative DT covered $\left(\mathrm{m}^{\circ} \mathrm{min}^{-1}\right)$ during all SSCG formats in our study ranged from $83.17 \pm 9.00$ to $91.67 \pm 8.47 \mathrm{~m} \cdot \mathrm{min}^{-1}$. These values were slightly lower than those previously reported in official soccer matches $\left(98.8 \pm 23.5\right.$ to $\left.118.7 \pm 12.2 \mathrm{~m} \cdot \mathrm{min}^{-1}\right)$ for age-matched samples ${ }^{3,4}$. Other important external load metrics such as HIR and sprinting have been explored due to their relationships with a variety of offensive and defensive actions linked to the decisive moments of the match (e.g., goal scoring) ${ }^{26}$. In this study, relative sprint distances were $1.85 \pm 1.89$ [SP+GS], $0.65 \pm$ $0.36[\mathrm{SP}+\mathrm{BP}], 1.84 \pm 1.88[\mathrm{RP}+\mathrm{GS}]$, and $0.95 \pm 0.78[\mathrm{RP}+\mathrm{BP}] \mathrm{m} \cdot \mathrm{min}^{-1}$. In agreement with our study, Castagna et al. ${ }^{3}$ also showed relative sprint distances of approximately $1.9 \mathrm{~m} \cdot \mathrm{min}^{-1}$ during a match in 12 -year-old soccer players. Harley et al. ${ }^{4}$ demonstrated that older players (U-14 to U-16: 4.7,3.9 and $4.3 \mathrm{~m} \cdot \mathrm{min}^{-1}$ ) reached higher relative sprint distances than their younger teammates (U-12 and U-13: 2.9 and $3.1 \mathrm{~m} \cdot \mathrm{min}^{-1}$ ) during official matches in a sample of elite English male players.

Increasing pitch length or width is a typical modification used by coaches when organizing SSCGs in their daily training routines ${ }^{5}$. Casamichana et al. ${ }^{12}$ showed that if the objective of SSCG is to provide highspeed movements, length manipulation should be prioritized in relation to width for the same playing surface. However, in our study, modifying pitch length and width (SP [length = width] vs. RP [length > width]) did not influence the majority of physical and technical performance measures. Significant difference was only noticed for distance covered in LIR between $\mathrm{SP}$ and RP, with higher values for the former condition (i.e., a wider pitch). The absence of difference for GPS-based running performance measures between SP and RP conditions could be attributed to the maintenance of the same pitch area per player $\left(148 \mathrm{~m}^{2}\right)$, unlike the study by Casamichana et al. ${ }^{12}$ in which this factor differed between conditions tested (100 to 330 $\mathrm{m}^{2}$ ). Regarding technical actions, longer passes occurred more often in longer pitch size than in wider pitch size. This can be partially attributed to more elongated positioning of players on the longitudinal axis when playing in RP formats ${ }^{17}$. Considering that the team is more spaced in the depth of the pitch, longer passes are required to move the ball and maintain possession. This finding is of practical relevance to coaches and 
technical staff as it suggests that good practice to develop player's ability to execute long passes would be to adopt spatial orientation that replicates the official pitch shape.

In our study, manipulation of tactical rules such as goal scoring or maintaining ball-possession had major influence on the player's physical demand and technical actions during SSCGs. With regard to technical performance, BP imposed higher technical involvement (i.e., higher number of long and short passes) than GS games. Our findings are comparable to previous studies showing that BP elicited higher number of passes than the GS condition in older soccer players ${ }^{15,27}$. Thus, coaches should to be aware that $\mathrm{BP}$ could be preferable in relation to GS to train these important technical traits during soccer practice with young players, includingthe years of sport initiation and specialization (11-13 years).

With regard to sprint activities, our findings are in agreement with other studies demonstrating that regular games (goal-scoring with GK) elicited greater distances covered at higher running intensities (14-20 $\mathrm{km} \cdot \mathrm{h}^{-1}$ ) and maximal speeds than ball-possession games in professional soccer players ${ }^{13,16,28}$. In opposition to these findings, Koklu et al. ${ }^{18}$ reported that SSCGs with goalkeepers elicited lower distance covered at HIR. These controversial findings between studies should be interpreted with caution due to the divergence in sample characteristics (pre-pubertal vs mid-pubertal vs. professional players) and speed thresholds used to define running intensity zones.

One of the most interesting findings of this research evidenced that games organized to score goals were the most effective approaches to replicate sprint demands (in terms of distance and number), regardless of pitch size, similar to findings in a real match scenario with age-matched samples ${ }^{3,4}$. Furthermore, there was a tendency of distances covered at HIA $(\mathrm{p}=0.098)$ and maximal speed $(\mathrm{p}=0.060)$ achieved during GS to be greater than in BP games, while the opposite was identified for the lowest running speed zones (e.g. MIR [p=0.055] and LIR [p=0.003 - significant]). Indeed, the higher physical demand during GS games (e.g., distance at sprinting) seems to be mainly explained by the increase in the player's linear behavior, adopting a movement pattern in the direction of the target in games with defined offensive side (GK condition) ${ }^{13}$. On the other hand, considering that $\mathrm{BP}$ games do not require teams to progress on the field during the offense, the aim of these games can be achieved with smaller displacement, mainly at the highest intensity zones, thus decreasing the external load in terms of HIR and sprinting efforts ${ }^{28}$. The findings of the current study confirmed that SSCGs proposed to maintain ball-possession (SP+BP and $\mathrm{RP}+\mathrm{BP})$ demanded the lowest relative sprint distances.

The GS condition significantly increased the distance covered in terms of walking in comparison to BP games. This finding might be due to the presence of a goalkeeper or the greater sprint distances in GS games. In the first case, the inclusion of GK would result in increasedtime that the ball is stopped in players' hands or feet due to shoots or passes, reducing 
the time that outfield players remain in contact with the ball and, in turn, increasing displacements in terms of walking ${ }^{18}$. For the latter situation, players may potentially have accumulated greater distances walking in order to recover from the greater amount of sprint activities (in terms of distance and number) performed during GS games ${ }^{3}$.

In addition to understanding the acute physical and technical responses to different SSCG formats, this study provided information about neuromuscular performance before and after the completion of SSCGs. It was observed that sprint and jump performance did not change after SSCGs, suggesting no decrement in power-speed related abilities. These findings are important for planning and prescribing training sessions for young soccer players entering adolescence (11-13 years). In general, players at these early ages experience lower level of fatigue than their older teammates ${ }^{29}$. Some studies have demonstrated that the level of neuromuscular fatigue manifested by the loss of performance in the ability to accelerate or jump after SSCG cessation is increased in older adolescent and professional soccer players ${ }^{21-23}$. Thus, the impact of SSCGs on neuromuscular performance in young soccer players seems to be age-dependent, progressively increasing as players pass through adolescence and reach adulthood.

According toour findings, it is possible to provide some advice of practical relevance to coaches and practitioners regularly involved in intensive training programs with young soccer players. The use of GS games should preferentially be adopted if the training session stimulus is devoted to produce more sprint actions (in terms of both number of sprint and sprinting distances). On the other hand, when designing training sessions, games prioritizing $\mathrm{BP}$ are highly recommended to develop short and long passes, with the latter being more frequent on longer pitch shape. In addition, SSCGs comprising two 10 -min bouts interspersed with 5 -min passive recovery ( $2: 1 \mathrm{~W}: \mathrm{R}$ ratio) can be useful to develop soccer-specific physical and technical components with low level of neuromuscular impairment in young players.

\section{CONCLUSIONS}

The present study using 5v5 SSCGs revealed that GS games demanded more sprint running episodes in terms of number and distance covered than BP games, although the latter was superior for eliciting higher technical involvement. Finally, our study also indicated that RP formats can be used to increase the occurrence of longer passes in male young soccer players aged $11-13$ years.

\section{COMPLIANCE WITH ETHICAL STANDARDS}

\section{Funding}

This research did not receive any specific grant from funding agencies in the public, commercial, or non-profit sectors. This study was funded by the authors. 


\section{Ethical approval}

Ethical approval was obtained from the local Human Research Ethics Committee -Federal University of Santa Catarina and protocol (No. 2.572.259) was written in accordance with standards set by the Declaration of Helsinki.

\section{Conflict of interest statement}

The authors have no conflict of interests to declare.

\section{Author Contributions}

Conceived and designed experiments: JFSNS, JPV, APV, JVW, GSP, AST, JFS. Performed experiments: JPV, APV, JVW, GSP. Analyzed data: JFSNS. Contributed with reagents/materials/analysis tools: JFSNS, PHGS, AST, JFS. Wrote the paper: JFSNS, JPV, APV, JVW, GSP, PHGS, AST, JFS.

\section{REFERENCES}

1. Saward C, Morris JG, Nevill ME, Nevill AM, Sunderland C. Longitudinal development of match-running performance in elite male youth soccer players. Scand J Med Sci Sports 2016;26(8):933-942.

2. Palucci Vieira LH, Aquino R, Moura FA, Barros RML, Arpini VM, Oliveira LP, et al. Team dynamics, running, and skill-related performances of brazilian U11 to professional soccer players during official matches. J Strength Cond Res 2019;33(8):2202-2216.

3. Castagna C, D'Ottavio S, Abt G. Activity profile of young soccer players during actual match play. J Strength Cond Res 2003;17(4):775-780.

4. Harley JA, Barnes CA, Portas M, Lovell R, Barrett S, Paul D, et al. Motion analysis of match-play in elite U12 to U16 age-group soccer players. J Sports Sci 2010;28,(13):1391-1397.

5. Clemente FM. Small-sided and conditioned games in soccer training: the science and practical applications. Singapore: Springer; 2016.

6. Clemente FM, Sarmento H. The effects of small-sided soccer games on technical actions and skills: A systematic review. Hum Mov 2020;21(3):100-119.

7. Hill-Haas SV, Coutts AJ, Dawson BT, Rowsell GJ. Time-motion characteristics and physiological responses of small-sided games in elite youth players: the influence of player number and rule changes. J Strength Cond Res 2010;24(8):2149-2156.

8. Sarmento H, Clemente FM, Harper LD, Costa IT, Owen A, Figueiredo AJ. Small sided games in soccer - a systematic review. Int J Perform Anal Sport 2018;18(5):693-749.

9. Lloyd RS, Oliver JL. The youth physical development model: a new approach to long-term athletic development. Strength Cond J 2012;34(3):61-72.

10. Reilly T. An ergonomics model of the soccer training process. J Sports Sci 2005;23(6):561-572.

11. Clemente FM, Sarmento H, Rabbani A, Van Der Linden CMIN, Kargarfard M, Costa IT. Variations of external load variables between medium- and large-sided soccer games in professional players. Res Sports Med 2019;27(1):50-59.

12. Casamichana D, Bradley PS, Castellano J. Influence of the varied pitch shape on soccer players physiological responses and time-motion characteristics during small-sided games. J Hum Kinet 2018;64:171-180.

13. Gaudino P, Alberti G, Iaia FM. Estimated metabolic and mechanical demands during different small-sided games in elite soccer players. Hum Mov Sci 2014;36:123-133. 
14. Casamichana D, Castellano J. Time-motion, heart rate, perceptual and motor behaviour demands in small-sides soccer games: effects of pitch size. J Sports Sci 2010;28(14):1615-1623.

15. Rebelo A, Brito J, Fernandes L, Silva P, Butler P, Mendez-Villanueva A, et al. Physiological, technical and time-motion responses to goal scoring versus ball possession in soccer small-sided games. Rev Port Ciênc Desporto 2011;11(1):409-412.

16. Belozo FL, Ferreira EC, Lizana CJR, Grandim G, Machado JC, Brenzikofer R, et al. The effect of the maintaining the ball possession on the intensity of games. Motriz: Rev Educ Fis 2016;22(1):54-61.

17. Folgado H, Bravo J, Pereira P, Sampaio J. Towards the use of multidimensional performance indicators in football small-sided games: the effects of pitch orientation. J Sports Sci 2019;37(9):1064-1071.

18. Köklü Y, Sert Ö, Alemdaroğlu U, Arslan Y. Comparison of the physiological responses and time-motion characteristics of young soccer players in small-sided games: the effect of goalkeeper. J Strength Cond Res 2015;29(4):964-971.

19. Folgado H, Lemmink KA, Frencken W, Sampaio J. Length, width and centroid distance as measures of teams tactical performance in youth football. Eur J Sport Sci 2014;14(1):S487-S492.

20. Olthof SBH, Frencken WGP, Lemmink KAPM. The older, the wider: on-field tactical behavior of elite-standard youth soccer players in small-sided games. Hum Mov Sci 2015;41:92-102.

21. Rebelo ANC, Silva P, Rago V, Barreira D, Krustrup P. Differences in strength and speed demands between $4 \mathrm{v} 4$ and $8 \mathrm{v} 8$ small-sided football games. J Sports Sci 2016;34(24):2246-2254.

22. Castillo D, Rodríguez-Fernández A, Nakamura FY, Sanchez-SanchezJ, RamirezCampillo R, Yanci J, et al. Influence of Different Small-Sided Game Formats on Physical and Physiological Demands and Physical Performance in Young Soccer Players. J Strength Cond Res (in press).

23. Castillo D, Yanci J, Sánchez-Díaz S, Raya-González J. An approach to the fatigue in young soccer players resulting from sided games. Sports 2019;7(7):174.

24. Clemente FM, Sarmento H, Costa IT, Enes AR, Lima R. Variability of technical actions during small-sided games in young soccer players. J Hum Kinet 2019;69:201-212.

25. Batterham AM, Hopkins WG. Making meaningful inferences about magnitudes. Sci Sports 2005;9:6-14.

26. Faude O, Koch T, Meyer T. Straight sprinting is the most frequent action in goal situations in professional football. J Sports Sci 2012;30(7):625-631.

27. Fernández-Espínola C, Abad Robles MT, Fuentes-Guerra FJ. Small-sided games as a methodological resource for team sports teaching: a systematic review. Int J Environ Res Public Health 2020;17(6):1884.

28. Clemente FM, Praça GM, Bredt SDGT, van der Linden CMI, Serra-Olivares J. External load variations between medium- and large-sided soccer games: ball possession games vs regular games with small goals. J Hum Kinet 2019;70:191-198.

29. Ratel S, Duché P, Williams C. A. Muscle fatigue during high-intensity exercise in children. Sports Med 2006;36(12):1031-1065.

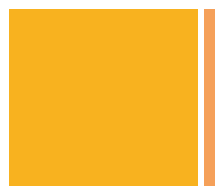

Corresponding author

José Francisco de Sousa Neto Segundo

Rua Cônego José Neves, $n^{\circ} 26$ A, centro, Sousa-PB,

CEP: 58800-190.

Email:zedejucelio18@hotmail.com 